\title{
$\begin{array}{ll}\text { Research Square } & \begin{array}{l}\text { Preprints are preliminary reports that have not undergone peer review. } \\ \text { They should not be considered conclusive, used to inform clinical practice, } \\ \text { or referenced by the media as validated information. }\end{array}\end{array}$
}

\section{Trends in Carriage of Extended Spectrum $\beta$-Lactamase and Carbapenemase Producing Enterobacteria Among HIV Infected Patients and Their Antimicrobial Susceptibility Patterns in Western-Cameroon}

Laure Brigitte Kouitcheu Mabeku ( $\sim$ laurebkouitcheu@yahoo.fr)

University of Dschang, Cameroon

Arnauld EFON EKANGOUO

University of Dschang, Cameroon

Jeannette Euranie Kouam Mewa

Regiional Hospital Bafoussam

\section{Research Article}

Keywords: Extended-spectrum beta-lactamase producing Enterobacteriaceae, Carbapenemase-producing Enterobacteriaceae, HIV infection, CD4 T lymphocytes, Cameroon.

Posted Date: December 30th, 2020

DOI: https://doi.org/10.21203/rs.3.rs-129678/v1

License: @ (i) This work is licensed under a Creative Commons Attribution 4.0 International License. Read Full License 


\section{Abstract}

Background: In Cameroon, studies on the prevalence of extended-spectrum beta-lactamase-producing Enterobacteriaceae (E-ESBLs) and carbapenemase-producing Enterobacteriaceae (CPE) among HIV infected individuals has not been investigated despite the progressively risen prevalence of HIV infection. The present study is intended determinate the magnitude of ESBL-E and CPE carriage among HIV-infected individuals.

Methods: Accordingly, 152 urine, 29 stool, 8 blood, 105 vaginal exudates and 14 wound swab sample were collected from 204 HIV negative and 104 HIV positive patients attending the Regional Hospital of Bafoussam-Cameroon from September 2016 to June 2017. From these specimen, Enterobacteriaceae were isolated based on their morphological features, Gram staining and biochemical characteristics using API 20E galleries (Biomerieux, France). For each HIV infected patient, the CD4 lymphocytes were measured using cytometric technique. The antimicrobial susceptibility was determined by KirbyBauer disc diffusion test against 11 antibiotics from $\beta$-lactam class. ESBL and CP in suspected strains was confirmed by double disk synergy test and combination disk test.

Results: The prevalence of Enterobacteriaceae infection among HIV positive patients was $46.15 \%$ versus $27.47 \%$ among HIV-negative ones ( $\mathrm{P}=0.0014)$. Among HIV positive patients, urine (47.91\%), vaginal exudates (31.25\%) and blood (4.16\%) specimens were mostly colonialized and Escherichia coli (37.5\%) the predominant species. The rate of Enterobacteraceae infection according to CD4 count range was $20.83 \%, 37.5 \%, 35.42 \%$ and $6.25 \%$ respectively for patients with CD4 T lymphocyte range up to 500, ]300-500], ]100-300] and $<100$ cells $/ \mathrm{mm}^{3}$. The overall resistance rates were 27.72 and $34.66 \%$ respectively among isolates from HIV negative and positive patients. The prevalence of ESBL, AmpC and carbapenemase producing Enterobacteriaceae infection was $16.34,12.5$, and $4.81 \%$ respectively among HIV infected patients versus 8.62 , 8.65 and $0 \%$ among HIV uninfected patients $(p=0.0055)$.

Conclusion: Our findings showed that HIV positive patients are significantly more affected by Enterobacteriaceae infection than negative ones and that the rate of these bacterial infection likely increases with decrease CD 4 counts. The present study also indicates that HIV positive patients are more likely to be infected by highly resistant organisms and had the highest carriage rate of ESBL, AmpC and carbapenemase producing Enterobacteriaceae compared to uninfected individuals in Western-Cameroon.

\section{Background}

Human immunodeficiency virus (HIV) is a causal agent of acquired immunodeficiency syndrome (AIDS) [1]. This retrovirus particularly attacks and kills CD4 T cells, resulting in the dysfunction and deregulation of the immune system and ultimately AIDS [2]. Because of the weakened immune system, HIV-infected individual can no longer ward off opportunistic infections [2-4].

Enterobacteriaceae are a large family of different types of bacteria that commonly cause infections both in healthcare settings and in communities. Several studies showed that Enterobacteriaceae infections are widely increased in HIV positive patients [5-9]. Enterobacteriaceae infection in immune compromised individual are associated with considerable morbidity, mortality and associated health care costs [10]. In such patients, the spectrum of Enterobacteriaceae infection is diverse, ranging from asymptomatic colonization to gastroenteritis, meningitis, wound infections, urinary tracts infections, septicaemia and urinary tract infections. This situation may increase the incidence and the progression of HIV infection to AIDS, an advanced stage of infection [11]. Enterobacteriaceae are now recognized as one of the most important threat for public health, due to the ambiguous resistance of these strains even to last classes of antibiotics. For example, some Enterobacteriaceae produce extended-spectrum beta-lactamases (ESBLs) which break down antibiotics such as penicillins and cephalosporins and alter their activity [1], thus making infections caused by ESBL-producing Enterobacteriaceae more difficult to manage. 
Studies on the prevalence of Enterobacteriaceae infection among HIV-infected patients and their susceptibility patterns to antimicrobial agents have been conducted in some African countries [12,13], but few of them correlated this prevalence to the immunological status of the patients. Concerning resistance mechanism, few studies on the prevalence of extended spectrum $\beta$-lactamase (ESBL) and carbapenemase producing members of Enterobacteriaceae (CPE) have been documented [14-16], despite the fact that Sub-Saharan Africa is the epicenter of the HIV epidemic [17].

Growing concerns exists over the prevalence of HIV infection in Cameroon. The prevalence of the HIV infection in Cameroon has progressively risen from $0.4 \%$ in 1987 to $1.2 \%$ in 1990 and from $4 \%$ in 1992 [18] to about $7 \%$ in 1997 and $11 \%$ in 2000 [19]. In 2004, the national prevalence stands at 5.5\% based on a Demographic and Health Survey [20].

Furthermore, there is a rising number of orphans from the HIV pandemic, with 122,670 cases reported in 2005 [21]. Despite this great negative progressive impact of HIV infection in Cameroon, the existing data obtained by research in the country concerning the prevalence of enteric bacterial infection among HIV patients in accordance with immunological status give an ill-defined picture. Also, data on their resistance pattern to antimicrobial agents and the magnitude of ESBL-E and CPE carriage among these immuno-compromised patients is scarce.

To address these knowledge gaps, the present study is intended to estimate the prevalence of Enterobacteriaceae infection among HIV-infected individuals attending the Regional Hospital of Bafoussam, Western Cameroon in correlation with CD4 cell counts, to elucidate the antimicrobial susceptibility patterns of Enterobacteriaceae isolated from these patients to $\beta$ lactam antibiotics and also to detect the production of $\beta$-lactamase enzyme among these isolates.

\section{Materials And Methods}

\section{Study design and setting}

This cross sectional study was conducted at the Bafoussam Regional Hospital, in the western region of Cameroon. The study population consisted of HIV-infected patients and HIV-uninfected patients attending the selected health facility from September 2016 to June 2017 and presenting signs and symptoms of infectious diseases. The detected type of infections were bacteremia, wound infections and those from the urinary, vaginal, and digestive tract. We employed a consecutive sampling for data collection, requesting consent from all volunteer patients (or from children's parents if participant was an adolescent) who fulfilled the eligibility criteria of the study. Exclusion criteria were (1) Patients under antibacterial therapy within the last two weeks (2) Patients with mixed types of infection; (3) Non-cooperative patients who refused to give their consent or to participate to the study; (4) HIV positive patients under ARV medication; (5) HIV patients who were severely ill and unable to provide sample. Pregnant and breastfeeding women were also excluded from the study.

\section{Ethical statement}

The study was conducted in accordance with the Declaration of Helsinki, and the protocol was approved by the Institutional Review Board of the Regional Hospital of Bafoussam (Ref. 1853/L/MINSANTE/SG/DRSPO/HRB/D) and the Centre Regional of Ethics Committee for Human Health Research (CRERSHC) (Ref. 00618/CRERSHC). Participation was voluntary and each subject involved in the study gave a written consent.

\section{Variables}

The socio-demographic data (age, gender) as well as others factors (previous history of antibiotics treatments, diagnosis for opportunistic infections) were requested from the volunteer subjects in a structured questionnaire. Confirmation of the HIV status was obtained from patients aware for their status through their medical records as well as information on the history on ARV medication. Eligible volunteer patients of the study were divided according to HIV status as HIV-positive individuals and HIV-negative individuals or control group. 
CD4 T-cell counts was determined for each confirmed HIV-positive participants. HIV-positive participants were then classified according to CD 4 cell count into 4 classes; CD 4 cell count $\otimes 500$ cells $/ \mathrm{mm}^{3}, \mathrm{CD} 4$ cell count between 300 and 500 cells $/ \mathrm{mm}^{3}$ ([500-300[), CD4 cell count between 100 and 300 cells $/ \mathrm{mm}^{3}$ ([300-100[) and CD4 cell count $\leq 100$ cells $/ \mathrm{mm}^{3}$.

\section{Sample collection}

Due to the fact that, Enterobacteriaceae affects several systems of the body, various clinical specimens were collected. They were midstream urine sample for urinary tract infection, stool sample for gastrointestinal tract infection, blood for bacteraemia, vaginal exudates for genital tract infections and wound swab for wound infections. All the collected samples were processed for culture and antibiotic susceptibility testing and the result were analyzed according to HIV status of participants.

Participants were instructed to collect stool and urine samples aseptically by the health personnel and were provided with sterile containers labelled with unique identification numbers for the collection of specimens.

The collection of vaginal exudates, wound swab and blood samples was done under aseptic conditions by well trained personnel of the hospital.

\section{Sample analysis}

Three milliliters $(3 \mathrm{ml})$ of venous blood was drawn from each patient, then $2 \mathrm{ml}$ of it transferred into a clean test tube and allowed to clot naturally by standing the sample at room temperature for $10 \mathrm{mn}$. Clear serum sample was obtained by spinning the tubes at $3000 \mathrm{rpm}$ for $5 \mathrm{mn}$ and used for HIV serology detection using OnSite HIV-1/2 Ab plus Comb Rapid Test-Cassette kit (CTK BIOTECH, San Diego USA).

The remaining $1 \mathrm{ml}$ of the blood was emptied into disposable EDTA tubes for CD 4 cell enumeration. The CD4 lymphocytes were measured by cytometric technique using a flux cytometer (Apogee Flow systems Limited®Apogee Flow Systems, Hertfordshire, United Kingdom).

For patients with clinical signs of bacteraemia an additional collection of blood $(2 \mathrm{ml})$ into a clean test tube was performed for culture.

Fecal samples were dissolved in sterile physiological water to obtain a $10 \%$ diluted solution and the mixture was homogenized using a Vortex mixer before culture.

\section{Culture and identification of Enterobacteriaceae}

The Clinical specimens were plated on solid cultures media; Urine samples, vaginal swab and wound swab on Mac Conkey agar and blood agar, Stools samples on Salmonella/Shigella (SS) agar and Mac Conkey agar, and Blood samples on Mueller Hinton Agar (MHA). Inoculated plates were incubated at $37^{\circ} \mathrm{C}$ for 24 hours. Isolated colonies were identified as Enterobacteriaceae species based on their morphological features, Gram staining and using API 20E galleries (Biomerieux, France).

\section{Antibacterial susceptibility testing}

All the isolates were subjected to antibiotic sensitivity test. Susceptibility of isolates to antibiotics was evaluated using Kirby-Bauer disc diffusion method according to the Clinical and Laboratory Standards Institute guidelines 2016 [22]. The antibiotic tested (Bioanalyse) were: Amoxicillin $(25 \mu \mathrm{g})$; amoxicillin + clavulanic acid (25/10 $\mu \mathrm{g})$; Piperacillin $(100 \mu \mathrm{g})$;

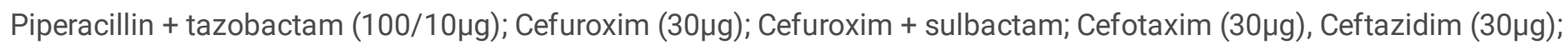
cefoxitin $(30 \mu \mathrm{g})$; Aztreonam $(30 \mu \mathrm{g})$, Imipenem $(10 \mu \mathrm{g})$. The tested Enterobacteria ceae species were classified as sensible, 
intermediate and resistant according to the cut-off point value of the inhibition zone recommended by the Clinical and Laboratory Standard Institute 2017 [23].

\section{Screening for potential ESBL-producing isolates}

The isolates that showed an inhibition zone size of $\leq 22 \mathrm{~mm}$ with ceftazidim $(30 \mu \mathrm{g})$ and/or $\leq 27 \mathrm{~mm}$ with cefotaxim $(30 \mu \mathrm{g})$ were considered as potential ESBL-producer and were selected for confirmation of ESBLs production.

\section{Confirmation of extended spectrum $\beta$-lactamase (ESBL)and AmpC production}

Isolates resistant to cephalosporin of the $3^{\text {rd }}$ generation (cefotaxim, ceftazidim) or to monobactam (aztreonam) in antibiotic sensitivity test were tested for ESBL and AmpC production by the Double Disc Synergy Test [24].

In a lawn culture of the strain into Mueller Hinton agar plate (MHA), amoxicillin/clavulanic acid (amoxyclav) disc $(20 \mu \mathrm{g}+10 \mu \mathrm{g})$ was placed in the centre of petri dish and cefotaxim $(30 \mu \mathrm{g})$, ceftazidim $(30 \mu \mathrm{g})$ and aztreonam $(30 \mu \mathrm{g})$ were placed on either side of amoxicillin/clavulanic acid disc at a distance of 18 to $20 \mathrm{~mm}$. A disc of cephalosporin of the $4^{\text {th }}$ generation; cefoxitin $(30 \mu \mathrm{g})$ was also placed at a distance of $15 \mathrm{~mm}$ from cefotaxim and ceftazidim disc. Plates were incubated at $37^{\circ} \mathrm{C}$ for 16 to 18 hours. Organism which showed extension inhibition zone of cefotaxim or ceftazidim or aztreonam towards amoxyclav disc was taken as ESBL screen positive. Blunting of inhibition zone of ceftazidim towards cefoxitin was taken as AmpC screen positive. Blunting of zone of inhibition of ceftazidim towards amoxyclav was taken as inducible AmpC positive.

\section{Screening and confirmation for carbapenemase producing isolates}

Isolates selected for this test were those known as ESBL producers from the above screening and those which were not susceptible to imipenem in antibiotic sensitivity test.

Confirmation of the carbapenemase class A production was evaluated using Double Disc Synergy Test [24]. In a lawn culture of the selected isolates, amoxicillin/clavulanic acid $(20 \mu \mathrm{g}+10 \mu \mathrm{g})$ and imipenem $(10 \mu \mathrm{g})$ discs were placed in petri dish at a distance of $20 \mathrm{~mm}$ from each other. Plates were incubated at $37^{\circ} \mathrm{C}$ for 16 to 18 hours. Organism which showed extension of inhibition zone of imipenem towards amoxyclav disc was taken as carbapenemase class $\mathrm{A}$ screen positive.

Phenotypic detection for Metallo beta Lactamases (MBL) or carbapenemase class B production was done by combination disc test using discs of Ceftazidim $(30 \mu \mathrm{g})$ and imipenem $(10 \mu \mathrm{g})$ alone and those combined with EDTA [25]. The stock solution of EDTA (Sigma-Aldrich, Germany) was prepared by dissolving anhydrous EDTA in distilled water at a concentration of $0.1 \mathrm{M}$. From this solution, $10 \mu \mathrm{l}$ was dispensed onto Ceftazidim $(30 \mu \mathrm{g})$ and imipenem $(10 \mu \mathrm{g})$ discs. The discs were dried and used within 60 minutes. The test was performed by inoculating the test organism on Mueller Hinton Agar and placing one disc of Ceftazidim $(30 \mu \mathrm{g})$ and imipenem $(10 \mu \mathrm{g})$ without any inhibitor and two discs of Ceftazidim $(30 \mu \mathrm{g})$ and imipenem $(10 \mu \mathrm{g})$, each containing EDTA. The agar plates were incubated at $37 \mathrm{C}$ overnight. The diameter of the growth inhibitory zone seen around the Ceftazidim $(30 \mu \mathrm{g})$ and imipenem $(10 \mu \mathrm{g})$ disc with EDTA was compared with that seen around the plain Ceftazidim $(30 \mu \mathrm{g})$ and imipenem $(10 \mu \mathrm{g})$ disc [25]. Regardless of the diameter zone, a $5 \mathrm{~mm}$ increase in zone diameter of Ceftazidim $(30 \mu \mathrm{g})$ and imipenem $(10 \mu \mathrm{g})$ tested in combination with EDTA versus Ceftazidim $(30 \mu \mathrm{g})$ and imipenem $(10 \mu \mathrm{g})$ zone size when tested alone was taken as carbapenemase class B or Metallo beta Lactamases production [25].

\section{Statistical Analysis}

Data were analysed using SPSS (version 2.0). We tested for association in categorical variables using the chi-square test, reporting corresponding $p$-values. Continuous variables such as CD4 count of participants were expressed as the mean \pm $\mathrm{SD}$ and comparison between CD 4 groups was performed using unpaired $t$ test and the corresponding $\mathrm{p}$ value was 
determined. A control group constituted by HIV negative participants was used for comparison between variable and the outcome. The level of statistical significance for the study was set at $p<0.05$. The outcome measure was the detection of the presence of Enterobacteriacea among clinical samples from HIV positive and HIV negative patients, the susceptibility of the isolated Enterobacteriaceae to $\beta$-lactam antimicrobial agents and the detection of beta-lactamase and carbapenemase enzyme production.

\section{Results}

\section{Prevalence of Enterobacteriaceae infection in the study population}

The study included three hundred and eight (308) patients, their age ranged from 1 to 85 years with mean $36.5 \pm 16.6$ years. They were made up of 104 HIV-positive patients ( 64 females and 40 males) and 204 HIV negative patients or control group (116 females and 88 males). From these participants, 308 clinical specimen were collected.

A total of one hundred and four (104) Enterobacteriaceae isolates were recovered from the 308 specimen collected, given an overall Enterobacteria infection rate of $33.77 \%$ in our study population. The prevalence of Enterobacteriaceae infection among HIV positive patients was 46.15\% (48/104) versus 27.47\% (56/204) among HIV-negative ones, suggesting that HIV positive patients were more prone to infection than negative ones. This difference was significant (OR: 2.265 (1.365-3.655) $P=0.0014)$.

The majority of the collected samples were urine samples (49.35\%) followed by vaginal swab samples (34.09\%) in both group of patients. Regarding the rate of infected sample, urine samples with $45.19 \%(47 / 104)$ were the most infected ones, followed by the vaginal exudates $(26.92 \%, 28 / 104)$ and stool samples $(17.31 \%, 18 / 104)$ in both HIV positive and negative patients. Also in both groups, the less infected biological specimen was blood with infection rate of 3.85\% (4/104). The proportion of infected urine (47.91 vs $42.85 \%$ ), vaginal exudates (31.25 vs $23.21 \%$ ) and blood (4.16 vs $3.57 \%$ ) samples was high in HIV positive patients compared to negative ones, while the opposite situation was noticed concerning wound swab (4.16 vs $8.92 \%)$ and stool (12.5 vs $21.42 \%)$ samples. However, the distribution of infected sample according to HIV status was not significant $\left(\mathrm{x}^{2}=2.851, \mathrm{P}=0.58\right)$ (Table 1$)$.

\section{Frequency of Enterobacteriaceae isolates}

Fourteen Enterobacteriaceae species were identified among the isolates in variable proportion; Escherichia coli (36.53\%), Klebsiella pneumoniae (8.65\%), Klebsiella rhinoscleromatis (1.92\%), Klebsiella oxytoca (7.53\%), Serratia odorifera (5.76\%), Serratia mascecens (4.80\%), Enterobacter aerogenes (4.80\%), Enterobacter cloacae (4.80\%), Enterobacter agglomerans (3.84\%), Citrobacter freundii (7.69\%), Proteus mirabillis (2.88\%), Proteus vulgaris (7.69\%), Salmonella spp (2.88\%), and Providencia rettgeri $(0.96 \%)$ (Table 2 ). The distribution of the identified species according to HIV status of the participants showed that Escherichia coli is the most predominant species among both HIV positive (35.41\%) and negative patients (37.5\%). This species was followed by Klebsiella, Proteus and Serratia species in the same proportion (14.58\%) among HIV positive patients and by Klebsiella (19.63\%) and Enterobacter (14.27\%) species among HIV negative patients. However, the distribution of identified species according to HIV status was not significant ( $\left.x^{2}=13.42, P=0.416\right)$ (Table 2). Also, Providencia rettgeri (1: 100\%), Enterobacter aerogenes (4: 80\%), Salmonella spp (2: 66.66\%) and Proteus spp (7: 63.63\%) were more isolated from HIV infected patients compared to HIV negative patients (0.00), (1: 20\%), (4: 36.36\%), and (1:

$33.33 \%$ ) respectively (Table 2). Klebsiellarhinoscleromatis and Enterobacter agglomerans were found only in HIV negative patients.

\section{Infection rate and CD4 count in HIV positive patients}

Blood samples were also collected to evaluate the immunological status by screening the amount of CD4 T lymphocytes in HIV positive patients. CD 4 count was ranged between 87 and 632 CD4 T lymphocytes per $\mathrm{mm}^{3}$ of blood sample with a 
mean value of $345.3 \pm 158.3$ cells $/ \mathrm{mm}^{3}$.

The mean value of CD4 count among HIV positive patients with Enterobacteriaceae infection was $260.3 \pm 121.4$ whereas it was $473.8 \pm 118.4$ cells $/ \mathrm{mm}^{3}$ among non-infected ones. This difference was significant $(t=6.015, p<0.0001)$. When examining the rate of Enterobacteriaceae infection according to CD4 range groups, we realized that out of the 48 Enterobacteria from HIV positive patients, 20.83\% (10/48), 37.5\% (18/48), 35.42\% (17/48) and 6.25\% (3/48) were isolated from patients with CD4 range above 500, [500-300[, [300-100[ and $\leq 100 \mathrm{cells} / \mathrm{mm}^{3}$ respectively. Escherichia coli was the species found at all CD4 range group with the highest proportion at CD4 up to $100 \mathrm{cells} / \mathrm{mm}^{3}$. Salmonella spp were present only at CD 4 up to 300 cells $/ \mathrm{mm}^{3}$. Klebsiella pneumonia was found only at CD4 less than $300 \mathrm{cells} / \mathrm{mm}^{3}$ and alone with Escherichia coli were the only species found at CD4 count $\leq 100$ cells $/ \mathrm{mm}^{3}$ (Figure 1).

\section{Antibiotic resistance pattern of Enterobacteriaceae according to HIV status}

The overall resistance rate were 27.72 and $35.49 \%$ respectively among isolates from HIV negative and positive patients. Resistance rate ranged from 4.16 to $72.74 \%$ among isolates from HIV positive patients and from 0 to $73.77 \%$ among those coming from HIV negative patients. The highest resistance rate to the tested antibiotics was detected among isolates from HIV positive patients except for Piperacillin + Tazobactam. Resistance rate of 42.3 vs $35.14,32.43$ vs $25,58.56$ vs 35.8 , 37.95 vs 11.1 and 50 vs $35.14 \%$ were noticed against piperacillin, cefotaxim, ceftazidim, cefoxitin and Cefuroxim respectively among isolates from HIV positive vs negative patients. Resistance rate against imipenem and cefuroxine/sulfobactam were detected only among isolates from HIV positive patients (Table 3). Resistance rate detected against amoxicillin, amoxicillin/clavulanic acid and aztréonam were independent of the HIV status of patients.

\section{Magnitude of ESBL, AmpC, and Carbapenemase producing Enterobacteriaceae}

Of all the Enterobacteriaceae isolates, 25\% (26/104) were positive for the screening test of ESBL production. From all the isolates, E. coli accounted for $34.61 \%$ (9/26), Enterobacter spp for 15.38\% (4/26), Klebsiella spp, Proteus spp and Citrobacter freundi for $11.54 \%(3 / 26)$ each. Only P. rettgeri was not detected as ESBL producer.

The overall prevalence of AmpC producing Enterobacteria infection was found to be $21.15 \%(22 / 104)$. The highest frequency of AmpC production was observed among E. coli 40.91\% (9/22) followed by Enterobacterspp 18.18\% (4/22) and Klebsiella spp. $18.18 \%$ (4/22). P. rettgeri and Salmonella spp were not detected as AmpC producers.

Approximately 5\% of isolates (4.81\%; 5/104) were detected as Carbapenemase producing Enterobacteria, 1.92\% (2/104) for class A and $2.88 \%$ (3/104) for class B. E. coli and Klebsiella pneumonia were the only carbapenemase producing Enterobacteria detected, in the proportion of 80 and $20 \%$ respectively (Tables 4 ).

The distribution of $\beta$ lactamase enzyme producing members varied significantly according to HIV status with the pic of prevalence among isolates coming from HIV infected patients $\left(X^{2} 18.32, p=0.0055\right)$. The prevalence of ESBL, AmpC and carbapenemase producing Enterobacteria infection was found to be $16.34,12.5$, and $4.81 \%$ respectively among HIV infected patients versus 8.62, 8.65 and $0 \%$ among HIV uninfected patients (Figure 2).

Among the 48 enteric bacterial isolates from HIV infected patients, 35.42 (17/48), 27.08 (13/48 and 10.42\% (5/48) were respectively ESBL, AmpC and carbapenemase producing Enterobacteria infection. Among the 56 enteric bacterial isolates from HIV uninfected patients $16.07(9 / 56), 16.07(9 / 56)$ and $0 \%(0 / 56)$ were respectively ESBL, AmpC and carbapenemase producing Enterobacteria infection.

\section{Discussion}


Human immunodeficiency virus (HIV) associated immunosuppression increases the vulnerability of patients to various infections [1]. As a result, Enterobacteriaceae infections are common and more likely to cause invasive conditions in HIVinfected patients than healthy individuals [3].

The overall rate of Enterobacteriaceae isolates from the various specimens in the current study was shown to be $46.15 \%$ (48/104) among HIV positive patients versus 27.47\% (56/204) in HIV uninfected patients. HIV positive patients were 2.265 times more prone to Enterobacteriaceae infection than HIV-negative ones (OR: 2.265 (1.365-3.655) P=0.0014), highlighting the fact that a compromised immunity resulting from HIV infection hampers the defense against microbes. Our finding is in accordance with previous studies reporting that rates of Gram-negative bacterial enteric infections are at least 10-fold higher among HIV-infected adults than in the general population [4-7].

The tract of infection to be study and the corresponding sample collected also affect the rate of enteric bacterial isolates as it was shown in the present study that $47.91,31.25,12.5,4.16$ and $4.16 \%$ of these pathogens were isolated respectively from urine, vaginal swab, stool, wound swab and blood samples respectively.

Regarding the rate of Enterobacteriaceae isolates according to the collected specimen and HIV status, our finding showed that urine (47.91 vs $42.85 \%$ ), vaginal exudates (31.25 vs $23.21 \%$ ) and blood (4.16 vs $3.57 \%$ ) samples were the most colonialized specimens among HIV infected persons compared to non-infected ones, suggesting that urogenital tract disorders and bacteraemia related to Enterobacteriaceae are common in HIV individual than gastrointestinal tract. This is true as it is reported that, among opportunistic infections, urinary tract infections accounts for $60 \%$ of AIDS defined illness [26].

The presence of bacteraemia among HIV infected individual compared to non-infected ones is not unexpected, since individuals with HIV infections are prone to salmonellosis and shigellosis which develops into bacteremia in more than 40 [27] and 50\% [28] of cases respectively. Bloodstream infection (BSI) is a frequent complication found in HIV-infected patients and is usually associated with a poor prognosis, responsible for the immediate cause of death in up to $32 \%$ of HIV-infected patients [29].

Concerning gastrointestinal tract infections, Enterobacteriaceae are commensal enteric flora usually not pathogenic in healthy individual. However, in HIV infected individuals, these bacterial are pathogenic because of the immunological response repression at the mucosal level that prevent intestinal idiopathic defense mechanisms [30].

The rate of Enterobacteriaceae isolates in the present study from stool sample of HIV infected individuals was shown to be $12.5 \%$. Previous studies reported similar rates of; $12.6 \%$ in southwest Ethiopia [31], 12.5\% in Cambodia [32] and 14.5\% in Peru [33]. However, rates reported in Uganda (19.2\%) [34], in India (29\%) [35], in Southwest Ethiopia (Jimma) (16\%) [36] and South Africa (43.3\%) [37] were higher than our findings. On the other hand, the current rate was higher than the rate of $8.3 \%$ reported among HIV-infected individuals from Arba Minch General Hospital, Southern Ethiopia [38]. The observed difference in the rates of Enterobacteriaceae isolated in stool sample could be attributed to differences in risk factors of the various populations. Since the probable source for most enteric infections is ingestion of contaminated food or water [4], factors like hand washing practice, contact with animals, consumption of raw food and others are indicated as potential factors for acquiring enteric bacterial infection [39].

After considering the colony morphology and biochemical characteristics, fourteen Enterobacteriaceae species were identified. Among the isolates, Escherichia coli was the most commonly identified, accounting for over $35.41 \%$, followed by Klebsiella species (14.58\%), Proteus and Serratia species (14.58\%) among HIV positive patients. Our findings concerning the commonest of Escherichia species among the isolates is similar to previous studies. In fact it reported that Salmonella, Shigella, Campylobacter and Escherichia coli are the most common enteric bacterial pathogens in HIV-infected patients [40] and etiologic agents with potential cause of severe illness among them [30]. Our data also revealed that $4.16 \%$ of the overall Enterobacteriaceae isolates were Salmonella spp and that $66.66 \%$ of these isolates were from HIV positive patients. 
Our findings correlated with previous reports that individuals with HIV infections have a 20- to 100-fold higher risk of salmonellosis than healthy individuals [27]. The present rate of Salmonella infection (4.16\%) is similar to that reported in Southern Ethiopia (5.1\%) [31], but was higher than a finding in Peru (1\%) [33], and Southern Ethiopia (2.8\%) [38], but rather lower than a result from Uganda (8.1\%) [34].

Previous studies reported very low rate of Shigella species in India (1\%) [35] and Cambodia (1.3\%) [32]. In the current study, no Shigella species was isolated among stool samples although using a specific medium for culture. In immunocompetent individuals, gastroenteritis with Shigella rarely develops into bacteremia, whereas up to $50 \%$ of AIDS patients with shigellosis become bacteremic [28]. This may be the reason of the absence of Shigella among our isolates since we did not culture blood in a specific medium for Shigella.

The absence of Campylobacter species or Clostridium difficile among the present enteric bacterial isolates is not unexpected, since we did not used specific culture medium for these species isolation.

The mean value of CD4 count among HIV positive patients with Enterobacteriaceae infection was whereas it was cells $/ \mathrm{mm}^{3}$ among non-infected ones. This difference was significant $(t=6.015, p<0.0001)$.

The distribution of enteric bacterial infection rate in HIV-infected individuals was affected by their immunological status. The mean value of CD4 count among HIV positive patients with Enterobacteraceae infection was $260.3 \pm 121.4$ whereas it was $473.8 \pm 118.4$ cells $/ \mathrm{mm}^{3}$ among non-infected ones, suggesting that HIV patients with low CD 4 count are more prone to Enterobacteraceae infection. Moreover, the rate of Enterobacteraceae isolation according to CD4 range groups was higher in HIV-patients who had low CD4+ T-lymphocyte counts. In fact, 20.83\% (10/48), 37.5\% (18/48), 35.42\% (17/48) and $6.25 \%$ (3/48) of Enterobacteriae isolated from HIV positive patients were respectively from patients with CD4 T lymphocyte range above 500, ]300-500], ]100-300] and $<100$ cells $/ \mathrm{mm}^{3}$. Such observations indicate that the rate of Enterobacteraceae infection among HIV positive patients increase when the CD4 level decrease and highlight the fact that HIV patients with low CD4 count are more prone to Enterobacteriaceae infection than uninfected ones. The present lower Enterobacteriaceae infection rate among CD 4 group $<100$ cells $/ \mathrm{mm}^{3}$ may simply reflect the low number of species isolated from this group of patient since they were not representative in our sample population. Similar high enteric bacterial isolation rate (80\%) in patients with CD4 T cell count less than 200 cells $/ \mathrm{mm}^{3}$ has been documented [41]. Such results highlight the fact that the progression of HIV infection to AIDS, and that the incidence to opportunistic infections increases while CD4 count decreases [42, 43]. In contrast, no significant difference was noticed in the bacterial isolation rate according to CD4 T cell count among patients in Southern Ethiopia [31]. Also, a study carry out in England reveals that $65.6 \%$ of the isolates were recorded in patients with higher CD4 T cell count [30].

Escherichia coli was the species found at all CD4 range group with the highest proportion at CD 4 up to 100 cells $/ \mathrm{mm}^{3}$. Such observation justified the predominance of Escherichia coli among Enterobateriaceae isolates in HIV positive patients as mentioned above. The presence of Klebsiella pneumonia at CD4 range less than $100 \mathrm{cells} / \mathrm{mm}^{3}$ may explain the highest prevalence of respiratory tract infection among HIV patients at an advanced stage of HIV infection.

Resistant of enteric bacteria to common antibiotics reduce the efficacy of these drugs to treat these infections and increase the frequency of therapeutic failure. The situation can become alarming for the immune-compromised patients as HIV infected individuals, who are at risk of repeated infections. In the present study, resistance rate of 27.72 and $35.49 \%$ were detected respectively among isolates from HIV negative and positive patients. Similarly, previous studies revealing higher resistance rate to antimicrobials among enteric bacterial coming from HIV-patients has been documented [44, 45]. Long term exposure to antimicrobials in order to cure or to prevent opportunistic infections in HIV patients may lead to the emergence of multidrug-resistant bacteria [46]. In fact, co-trimoxazole is recommended to HIV adults and children born to HIV-infected women as prophylaxis measures against opportunistic infection [47]. The continuous exposure to this drug 
has result to the emergence of co-trimoxazole-resistant bacteria in HIV population and the therapeutic failure against bacterial infections.

$\beta$-lactam antibiotics such as penicillins, cephalosporins and carbapenems are the most commonly used antibacterial drugs. The predominant drug resistance mechanism against $\beta$-lactam antibiotics among Gram-negative bacteria is the production of $\beta$-lactamase enzymes. Most important $\beta$-lactamase enzymes are extended spectrum $\beta$-lactamases (ESBLs), AmpC $\beta$ - lactamase (AmpC) and Metallo $\beta$-lactamase (MBL). In this study, bacterial isolates from HIV infected patients were highly resistant to cephalosporins (cefotaxim, ceftazidim, cefoxitin, cefuroxim) and lowly to cefuroxine/sulfobactam and piperacillin/tazobactam, characteristics which are specific to extended spectrum $\beta$-lactam antibiotics producing microorganisms. Few of them were also resistant to imipenem. Thus, the magnitude of extended-spectrum betalactamases (ESBLs) and carbapenemase production were evaluated among these isolates according to HIV status of the participants.

Our data showed that 25\% (26/104), 21.15\% (22/104) and 4.81\% (5/104) of the isolated Enterobacteriaceae were found to be ESBL, AmpC and carbapenemase producing bacterial infection independent of the HIV status. The highest frequency of ESBL and AmpC production was observed among E. coli, followed by Enterobacterspp whereas carbapenemase producing Enterobacteriaceae were predominantly E. coli and Klebsiella pneumonia. The overall prevalence of ESBL, AmpC and carbapenemase producing Enterobacteria infection was $16.34,12.5$, and $4.81 \%$ respectively among HIV infected patients versus 8.62, 8.65 and $0 \%$ among HIV uninfected patients, suggesting that isolates coming from HIV infected patients are more prone to produce $\beta$-lactamase enzyme than those from uninfected ones $\left(X^{2} 18.32, p=0.0055\right)$. Moreover, among the Enterobacteriaceae isolates from HIV infected patients, 35.42, 27.08 and 10.42\% respectively were ESBL, AmpC and carbapenemase producing enteric bacterial infection. The current findings on the prevalence of extended spectrum $\beta$ lactamases producing Enterobacteria among HIV infected patients (35.42\%) is comparable with studies from Ethiopia like Jimma (38.4\%) [48], and Harar (33.3\%) [49]. However this prevalence was higher compared with that documented in studies from others parts of Ethiopia (25\%) [50], (21.4\%) [51] and Saudi Arabia (22\%) [52] and significantly higher with reports in the United States (8.6\%) [53] and the United Kingdom (1\%) [54]. On the other hand, it was lower than reports from different African countries such as Ghana (49.3\%) [55], Addis Ababa (52\%) [56] and Uganda (62\%) [57]. The variation might be due to the difference in sampling population, the policy of antibiotics prescription, as well as socio-cultural and economic factors.

In Cameroon, few studies on the extent of E-ESBL circulating strains among the general population have been investigated but none among HIV infected patients. A ESBL carriage of $12 \%$ and $16 \%$ was reported among enteric bacteria isolates respectively in HIV uninfected patients in Yaounde and in the community of Ngaoundéré $[59,58]$. Approximately 45\% (45.3\%) enteric bacteria produced ESBL was isolated from women with urinary tract infections in Yaounde-Cameroon prior to antibiotics use [60]. The higher prevalence of extended spectrum $\beta$-lactamases producing Enterobacteria of this study compared with the aforementioned reports may be due to the difference in sampling population. In fact, HIV patients are in high risk for ESBL carriage because they are commonly subjected to infections and hospitalization, and more likely to consume antimicrobial agents than HIV negative persons. This may also justify the present high prevalence of AmpC (27.08\%) and carbapenemase (10.42\%) producing Enterobacteria infection among HIV-patients compared to uninfected persons. Carbapenems are antibiotics usually used to treat extended-spectrum and AmpC $\beta$-lactamases producing pathogens [61]. However, the spread of enzymes that break down these antibiotics has been reported [62]. This situation may further compromise therapeutic alternatives using every beta-lactam antibiotics but also those using non-beta-lactam as a connection with resistance determinants which can easily disseminated, since carbapenemase mediated resistance are usually transposon- and/or integron-encoded determinants [63].

\section{Conclusion}


Our findings showed that HIV positive patients are significantly more affected by Enterobacteriaceae infection than negative ones and that the rate of these bacterial infection likely increases with decrease CD 4 counts. The present study also indicates that HIV positive patients are more likely to be infected by highly resistant organisms and had the highest carriage rate of ESBL, AmpC and carbapenemase producing Enterobacteriaceae compared to uninfected individuals in Western-Cameroon. Hence, HIV patients act as the main reservoir of ESBL, AmpC and carbapenemase producing pathogens in our community. Further studies need to be performed in a large scale in order to fully elucidate the ESBL, $\mathrm{AmpC}$ and carbapenemase carriage in Cameroon. Future efforts should focus on determining the presence of transferable resistance plasmids through genomic analysis in order to track the spread of these resistance genes within the population.

\section{Abbreviations}

Pen TEM

Penicillinase TEM, Pen RI:Penicillinase resistant to inhibitors, ESBL:Extended spectrum beta Lactamases, AmpC:AmpC beta Lactamases, Carbap A:Carbapenemase class A, MBL:Metallo beta Lactamases. E-ESBLs:Extended-spectrum betalactamase-producing Enterobacteriaceae, CPE:Carbapenemase-producing Enterobacteriaceae.

\section{Declarations}

\section{Acknowledgment}

We acknowledge the support of the staffs of the Regional Hospital of Bafoussam-Cameroon who facilitated recruitment of patients for this research. We thank the participating patients for their cooperation.

\section{Author Contributions}

KMLB conceived the study, designed the experiments and supervised the work. KMJE participated in the recruitment of subjects and performed the physical examination of participants. EEA collected the samples from participants. KMLB and EEA carried out the analysis and provided the facilities for the study. KMLB drafted the manuscript. All the authors read and approved the final manuscript.

\section{Funding}

This research did not receive any specific grant from funding agencies in the public, commercial, or not-for-profit sectors.

\section{Availability of data and materials}

The datasets used and/or analyzed during the current study are available from the corresponding author on reasonable request.

\section{Ethics statement}

The study was approved by the Centre Regional Ethics committee for Human Health Research (Approval $\left.n^{\circ} 00618 / C R E R S H C / 2016\right)$. Each patient provided written informed consent to participate in the study. Children were enrolled after their parents or legal guardians provided a written informed consent.

\section{Competing Interests}

The authors declare that they have no competing interests.

\section{References}


1. Rampha IR, Ambrose PG. Extended-spectrum beta-lactamases and clinical outcomes: current data. Clin Infect Dis. 2006; 42 Suppl 4:S164-72.

2. Woerther PL, Burdet C, Chachaty E, Andremont A. Trends in human fecal carriage of extended-spectrum $\beta$-lactamases in the community: toward the globalization of CTX-M. Clin Microbiol Rev. 2013; 26(4):744-58.

3. National AIDS/STD control programme. Handbook on HIV Infection and AIDS for Health Workers. Federal Ministry of Health, Abuja, Nigeria. 1992; 12-14.

4. Oyeyipo 00, Azuounwu 0, Owhoeli O. Prevalence of HIV antibodies in patients with clinical tuberculosis in Port Harcourt. International J Biosci. 2010; 5(30):65-68.

5. Downs JH. The gastrointestinal tract and HIV pathogenesis. S Afr J Clin Nutr. 2010; 23: 565-8.

6. Angulo FJ, Swerdlow DL. Bacterial enteric infections in persons infected with human immunodeficiency virus. Clin Infect Dis. 1995; 21 Suppl 1:S84-93.

7. Sanchez TH, Brooks JT, Sullivan PS, et al. Bacterial diarrhea in persons with HIV infection, United States, 1992-2002. Clin Infect Dis. 2005; 41(11):1621-1627.

8. Wilcox CM, Saag MS. Gastrointestinal complications of HIV infection: changing priorities in the HAART era. Gut. 2008; 57(6):861-870.

9. Hung CC, Hung MN, Hsueh PR, et al. Risk of recurrent nontyphoid Salmonella bacteremia in HIV-infected patients in the era of highly active antiretroviral therapy and an increasing trend of fluoroquinolone resistance. Clin Infect Dis. 2007; 45(5):e60-67.

10. Zimmerman FS, Assous MV, Bdolah-Abram T, Lachish T, Yinnon AM, Wiener-Well Y. Duration of carriage of carbapenem-resistant Enterobacteriaceae following hospital discharge. Am. J. Infect.Control. 2013; 41:190-194.

11. Jean-Marie Liesse lyamba, José Mulwahali Wambale, Ntondo za Balega, Takaisi- Kikuni. Antimicrobial susceptibility patterns of enterobacteriaceae isolated from HIV-infected patients in Kinshasa. Pan African Medical Journal. 2014; ISSN: 1937-8688.

12. Cotton MF, Wasserman E, Smit J, Whitelaw A, Zar HJ. High incidence of antimicrobial resistant organisms including extended spectrum beta-lactamase producing Enterobacteriaceae and methicillin-resistant Staphylococcus aureus in nasopharyngeal and blood isolates of HIV-infected children from Cape Town, South Africa. BMC Infect Dis. 2008; 8:40.

13. Mwansa J, Mutela K, Zulu I, Amadi B, Kelly P. Antimicrobial sensitivity in enterobacteria from AIDS patients, Zambia. Emerg Infect Dis. 2002; 8(5):540.

14. Tansarli GS, Poulikakos P, Kapaskelis A, Falagas ME. Proportion of extended-spectrum $\beta$-lactamase (ESBL)-producing isolates among Enterobacteriaceae in Africa: evaluation of the evidence-systematic review. J Antimicrob Chemother. 2014; 69:1177-1184.

15. Storberg V. ESBL-producing Enterobacteriaceae in Africa-a non-systematic literature review of research published 2008-2012. Infect Ecol Epidemiol. 2014; 4:20342.

16. Bourjilat F, Bouchrif B, Dersi N, Claude JD, Amarouch Hetal. Emergence of extended-spectrum beta-lactamasesproducing Escherichia coli in community-acquired urinary infections in Casablanca, Morocco. J Infect Dev Ctries. $2011 ; 5: 850-855$.

17. UNAIDS.2015. UNAIDS factsheet. www.unaids.org/ sites/ default/ files/ media_asset/ 20150901_FactSheet_2015_en.pdf [accessed23/01/2017].

18. Garcia-Calleja, J.M.; Abbenyi, S. Review of HIV prevalence studies in Cameroon. AIDS Inform. Bull. 1993; 1:5-6.

19. Sentinel Surveillance of the Ministry of Public Health, Cameroon, 2000.

20. Institut National de la Statistique Enquête Démographique et de Santé Cameroun 2004. http://www.measuredhs.com/countries/, accessed April 15, 2008.

21. National AIDS Control Committee's Annual Reports, Cameroon, 2005.

Page $12 / 20$ 
22. Clinical Laboratory Standards Institute. Performance standards for antimicrobial susceptibility testing. Vol. 26th ed., CLSI supplement M100S. Wayne, PA. 2016.

23. Antibiogram Committee of the French Society of Microbiology Recommendation. CASFM 2017: 117. . Consulté le 1112-2017.

24. Clinical Laboratory Standards Institute. Performance standards for antimicrobial susceptibility testing: twenty-first Informational Supplement M100-S21. Wayne, PA. 2011.

25. Tsakris A, Poulou A, Pournaras S, Voulgari E, Vrioni G, Themeli Digalaki KA. Simple phenotypic method for the differentiation of metallo-lactamases and class A KPC carbapenemases in Enterobacteriaceae clinical isolates. J Antimicrob Chemother. 2010; 65:1664-71.

26. Hidron Al, Kempker R, Moanna A, Rimland D. Methicillin-resistant Staphylococcus aureus in HIV-infected patients. Infection and Drug Resistance. 2010; 3:73-86.

27. Cummings PL, Sorvillo F, Kuo T. Salmonellosis-related mortality in the United States, 1990-2006. Foodborne Pathog Dis. 2010; 7:1393-9.

28. Framm Sr, Soave R. Agents of diarrhea. Med Clin North Am. 1997; 81:427-47.

29. Tumbarello M, Tacconelli E, Caponera S, Cauda R, Ortona L. The impact of bacteremia on HIV infection. Nine years experience in a large Italian university hospital. The Journal of Infection. 1995; 31:123-131.

30. Datta D, Gazzard B, Stebbing J. The diagnostic yield of stool analysis in 525 HIV-1-infected individuals. AIDS. 2003; 17:1711-3.

31. Ayele Kebede1, Solomon Aragie1and Techalew Shimelis. The common enteric bacterial pathogens and their antimicrobial susceptibility pattern among HIV-infected individuals attending the antiretroviral therapy clinic of Hawassa university hospital, southern Ethiopia. Antimicrobial Resistance and Infection Control. 2017; 6:128.

32. Chhin S, Harwell JI, Bell JD, Rozycki G, Ellman T, Barnett JM, Ward H. Etiology of chronic diarrhea in antiretroviral-naïve patients with HIV infection admitted to Norodom Sihanouk hospital, Phnom Penh, Cambodia. Clin Infect Dis. 2006; 43:925-32.

33. Cárcamo C, Hooton T, Wener MH, Weiss NS, Gilman R, Arevalo J. Etiologies and manifestations of persistent diarrhea in adults with HIV-1 infection: a case-control study in lima, Peru. JID. 2005; 191:11-9.

34. Brink AK, Mahe C, Watera C, Lugada E, Gilks C, Whitworth J. Diarrhea, CD4 counts and enteric infections in a community-based cohort of HIV-infected adults in Uganda. J Inf Secur. 2002; 45:99-106.

35. Uppal B, Kashyap B, Bhalla P. Enteric pathogens in HIV/AIDS from a tertiary care hospital. Indian J Community Med. $2009 ; 34: 237-42$.

36. Awole M, Gebre-Selassie S, Kassa T, Kibru G. Isolation of potential bacterial pathogens from the stool of HIV-infected and HIV-non-infected patients and their antimicrobial susceptibility patterns in Jimma hospital, south west Ethiopia. Ethiop Med J. 2002; 40:353-64.

37. Obi CL, Bessong PO. Diarrhoeagenic bacterial pathogens in HIV-positive patient with diarrhea in rural communities of Limpopo Province, South Africa. JHPN. 2002; 20:230-4.

38. Ayele AA, Tadesse D, Manilal A, Yohanes T, Seid M, Shewangizaw Mekuria M. Prevalence of enteric bacteria and enteroparasites in human immunodeficiency virus-infected individuals with diarrhoea attending antiretroviral treatment clinic, Arba Minch General Hospital, southern Ethiopia. New Microbes and New Infections. 2020; 38: C.

39. Huang DB, Zhou J. Effect of intensive hand washing in the prevention of diarrheal illness among patients with AIDS: a randomized controlled study. J Med Microbiol. 2007; 56:659-63.

40. Shah S, Kongre V, Kumar V, Bharadwaj R. A Study of parasitic and bacterial pathogens associated with diarrhea in HIVpositive patients. Cureus. 2016; 8(9). 
41. Sanchez TH, Brooks JT, Sullivan PS, Juhasz M, Mintz E, Dworkin MS. Bacterial diarrhea in persons with HIV infection, United States. Clin Infect Dis. 2005; 41:1621-2.

42. Dilys Morgan CM, Billy Mayanja, James A G Whitworth. Progression to symptomatic disease in people infected with HIV1 in rural Uganda: prospective cohort study. British Medical Journal. 2002; 324:193-7.

43. Mellors JM, Giorgi A, Margolick JV, Tassoni JB, Gupta CJ, Kingsley P, Todd LA, Saah JA, Detels AJ, Phair R, Rinaldo JP, Jr CR. Plasma viral load and CD4 + lymphocytes as prognostic markers of HIV-1 infection. Ann Intern Med. 1997; 126(12):946-54.

44. Kownhar H, Shankar EM, Rajan R, Vengatesan A, Rao UA. Prevalence of campylobacter jejuni and enteric bacterial pathogens among hospitalized HIV-infected versus non-HIV infected patients with diarrhoea in southern India. Scand J Infect Dis. 2007; 39:862-6.

45. Mwansa J, Mutela K, Zulu I, Amadi B, Kelly P. Antimicrobial sensitivity in Enterobacteria from AIDS patients, Zambia. Emerg Infect Dis. 2002; 8:92-3.

46. Rossit ARB, Gonçalves ACM, Franco C, et al. Etiological agents of diarrhea in patients infected by the HIV-1. a review. Rev Inst Med trop S Paulo. 2009; 5:59-65.

47. World Health Organization. Provisional WHO/ UNAIDS Secretariat Recommendations on the Use of Cotrimoxazole Prophylaxis in Adults and Children Living with HIV/AIDS in Africa. Geneva, Switzerland: WHO/UNAIDS; 2000.

48. Siraj SM, Ali S, Wondafrash B. Extended-spectrum $\beta$-lactamase production in Klebsiella pneumoniae and Escherichia coli at Jimma University Specialized Hospital, South-West, Ethiopia. Mol Microbiol Res. 2015; 5(1):1-9.

49. Seid J, Asrat D. Occurrence of extended spectrum beta-lactamase enzymes in clinical isolates of Klebsiella species from Harar region, Eastern Ethiopia. Acta Trop. 2005; 95:143-48.

50. Mulisa G, Selassie LG, Jarso G, Shiferew T, Zewdu A, et al. Prevalence of extended spectrum beta-lactamase producing Enterobacteriaceae: a cross sectional study at Adama Hospital, Adama. J Emerg Infect Dis. 2016; 1(1):1-6.

51. Mulualem Y, Kasa T, Mekonnen ZSS. Occurrence of extended spectrum beta-lactamases in multidrug resistant Escherichia coli isolated from a clinical setting in Jimma University specialized hospital, Jimma, Southwest Ethiopia. East Afr J Public Heal. 2012; 9(2):58-61.

52. Kandeel A. Prevalence and risk factors of extended-spectrum $\beta$-lactamases producing Enterobacteriaceae in a general hospital in Saudi Arabia. J Microbiol Infect Dis. 2014; 4(2):50-54.

53. Reuland EA, Al Naiemi N, Kaiser AM, Heck M, Kluytmans JA, et al. Prevalence and risk factors for carriage of ESBLproducing Enterobacteriaceae in Amsterdam. J Antimicrob Chemother. 2016; 71:1076-82.

54. Enoch DA, Brown F, Sismey AW, Mlangeni DA, Curran MD, et al. Epidemiology of extended-spectrum beta-lactamaseproducing Enterobacteriaceae in a UK district hospital; an observational study. J Hosp Infect. 2012; 81(4):270-77.

55. Obeng-nkrumah N, Twum-danso K, Krogfelt KA, Newman MJ. High levels of extended-spectrum beta-lactamases in a major teaching hospital in Ghana: the need for regular monitoring and evaluation of antibiotic resistance. Am J Trop Med Hyg. 2013; 89(5):960-64.

56. Desta K, Woldeamanuel Y, Azazh A, Mohammod H, Desalegn D, et al. High gastrointestinal colonization rate with extended-spectrum $\beta$-Lactamase-Producing Enterobacteriaceae in hospitalized patients: emergence of carbapenemase-producing K. pneumoniae in Ethiopia. PLoS One Med. 2016; 11(8):1-14.

57. Kateregga JN, Kantume R, Atuhaire C, Lubowa MN, Ndukui JG. Phenotypic expression and prevalence of ESBLproducing Enterobacteriaceae in samples collected from patients in various wards of Mulago Hospital, Uganda. BMC Pharmacol Toxicol 2015; 2015:14-19.

58. Gangoue-Pieboji J, Bedenic B, Koulla-Shiro S, Randegger C, Adiogo D, Ngassam P et al. Enterobacteriaceae produisant des bêta-lactamases à spectre étendu à Yaoundé, Cameroun. J Clin Microbiol. 2005; 43(7):3273-3277.

59. Carine Magoué Lonchel, Cécile Meex, Joseph Gangoué-Piéboji, Raphaël Boreux, Marie-Claire Okomo Assoumou et al. Proportion of extended-spectrum B-lactamase-producing Enterobacteriaceae in community setting in Ngaoundere, 
Cameroon. BMC Infect Dis. 2012; 9: 53.

60. Djuikoue IC, Njajou O, Kamga HG, Fokunang C, Bongoe A, Bruno EO et al. Prévalence des $\beta$-lactamases CTX-M chez Escherichia coli provenant d'infections urinaires acquises dans la communauté et facteurs de risque associés chez les femmes au Cameroun. J Epidemiol Res. 2017; 3(1):51.

61. Ikonomidis A, Tokatlidou D, Kristo I. Outbreaks in distinct regions due to a single Klebsiella pneumoniae clone carrying a blaVIM-1 metallo-b-lactamase gene. J Clin Microbiol. 2005; 43:5344-7.

62. Queenan AM, Bush K. Carbapenemases The versatile $\beta$-lactamases. Clin Microbiol Rev. 2007; 20:440-58.

63. Thomson KS. Extended-Spectrum-Lactamase, ampC and carbapenemase issues. J Clin Microbiol. 2010; 48:1019-25.

\section{Tables}

Table 1. Distribution of Enterobacteriaceae colonized samples according to HIV status

\begin{tabular}{|llllll|}
\hline Samples & $\begin{array}{l}\text { Sample collected } \mathbf{N} \\
(\%)\end{array}$ & $\begin{array}{l}\text { Infected sample N } \\
(\%)\end{array}$ & $\begin{array}{l}\text { HIV Positive patients } \\
\mathbf{N}(\%)\end{array}$ & $\begin{array}{l}\text { HIV negative patients } \\
\mathbf{N}(\%)\end{array}$ & $\begin{array}{l}\mathbf{X}^{2}, \\
(\mathbf{P} \\
\text { value })\end{array}$ \\
\hline Urine & $152(49.35)$ & $47(45.19)$ & $23(47.91)$ & $24(42.85)$ & \\
\hline $\begin{array}{l}\text { Vaginal } \\
\text { swab }\end{array}$ & $105(34.09)$ & $28(26.92)$ & $15(31.25)$ & $13(23.21)$ & \\
\hline $\begin{array}{l}\text { Wound } \\
\text { Swab }\end{array}$ & $14(4.55)$ & $7(6.73)$ & $2(4.16)$ & $5(8.92)$ & \\
\hline Stool & $29(9.46)$ & $18(17.31)$ & $6(12.5)$ & $12(21.42)$ & \\
\hline Blood & $8(2.60)$ & $4(3.84)$ & $2(4.16)$ & $2(3.57)$ & \\
\hline Total (\%) & $308(100)$ & $104(33.77)$ & $48(46.15)$ & $56(53.84)$ & \\
\hline
\end{tabular}

Table 2: Enterobacteriaceae species distribution in HIV-positive and HIV-negative patients 


\begin{tabular}{|c|c|c|c|c|c|}
\hline \multirow{2}{*}{$\begin{array}{l}\text { Enterobacteriaceae } \\
\text { species }\end{array}$} & \multirow{2}{*}{$\begin{array}{l}\text { Number of } \\
\text { isolated } \\
\text { species (\%) }\end{array}$} & \multicolumn{2}{|c|}{ HIV Positive patients } & \multicolumn{2}{|c|}{ HIV-negative patients } \\
\hline & & $\begin{array}{l}\text { Number } \\
(\%)\end{array}$ & $\begin{array}{l}\text { Proportion of a specie on } \\
\text { the overall isolated } \\
\text { species (\%) }\end{array}$ & $\begin{array}{l}\text { Number } \\
(\%)\end{array}$ & $\begin{array}{l}\text { Proportion of a specie } \\
\text { on the overall isolated } \\
\text { species }(\%)\end{array}$ \\
\hline Escherichia coli & $38(36.53)$ & $17(35.42)$ & 44.74 & $21(37.5)$ & 52.26 \\
\hline $\begin{array}{l}\text { Klebsiella } \\
\text { pneumonia }\end{array}$ & $8(8.65)$ & $2(4.17)$ & 25 & $6(10.71)$ & 75 \\
\hline $\begin{array}{l}\text { Klebsiella } \\
\text { hinoscleromatis }\end{array}$ & $2(1.92)$ & $0(0)$ & 0.00 & $2(3.57)$ & 100 \\
\hline Klebsiella oxytoca & $8(7.69)$ & $5(10.42)$ & 62.5 & $3(5.36)$ & 37.5 \\
\hline Serratia odorifera & $6(5.76)$ & $2(4.17)$ & 33.33 & $4(7.14)$ & 66.66 \\
\hline $\begin{array}{l}\text { Serratia } \\
\text { mascecens }\end{array}$ & $5(4.80)$ & $2(4.17)$ & 40 & $3(5.36)$ & 60 \\
\hline $\begin{array}{l}\text { Enterobacter } \\
\text { aerogenes }\end{array}$ & $5(4.80)$ & $4(8.33)$ & 80 & $1(1.78)$ & 20 \\
\hline $\begin{array}{l}\text { Enterobacter } \\
\text { cloacae }\end{array}$ & $5(4.80)$ & $2(4.17)$ & 40 & $3(5.36)$ & 60 \\
\hline $\begin{array}{l}\text { Enterobacter } \\
\text { agglomerans }\end{array}$ & $4(3.84)$ & $0(0)$ & 0.00 & $4(7.14)$ & 100 \\
\hline Citrobacter freundii & $8(7.69)$ & $4(8.33)$ & 50 & $4(7.14)$ & 50 \\
\hline Proteus mirabillis & $3(2.88)$ & $2(4.17)$ & 66.66 & $1(1.78)$ & 33.33 \\
\hline Proteus vulgaris & $8(7.69)$ & $5(10.42)$ & 62.5 & $3(5.36)$ & 37.5 \\
\hline Salmonella spp & $3(2.88)$ & $2(4.17)$ & 66.66 & 1(1.78) & 33.33 \\
\hline $\begin{array}{l}\text { Providencia } \\
\text { rettgeri }\end{array}$ & $1(0.96)$ & $1(2.08)$ & 100 & $0(0)$ & 0.00 \\
\hline Total & 104 & 48 & & 56 & \\
\hline $\mathrm{X}^{2},(\mathrm{P}$ value $)$ & $13.42,(0.416)$ & & & & \\
\hline
\end{tabular}

Table 3: Resistance rate to the tested antibiotics according to HIV status of patients 


\begin{tabular}{|llllll|}
\hline Antibiotics & Breakpoint & \multicolumn{2}{l}{ HIV negative patients } & \multicolumn{2}{l|}{ HIV positive patients } \\
\cline { 5 - 7 } & $(\mathrm{mm})$ & Number & Resistance & Number & Resistance \\
& & of species & rate (\%) & of species & rate (\%) \\
\hline Amoxicillin & $14-17$ & 56 & 73.77 & 48 & 72.74 \\
\hline Amoxicillin + clavulanc acid & $14-17$ & 56 & 58.53 & 48 & 60.53 \\
\hline Piperacillin + Tazobactam & $18-20$ & 56 & 10.86 & 48 & 4.16 \\
\hline Piperacillin & $18-20$ & 56 & 35.14 & 48 & 42.3 \\
\hline Aztreonam & $16-21$ & 56 & 19.54 & 48 & 17.19 \\
\hline Imipenem & $14-15$ & 56 & 0 & 48 & 10.41 \\
\hline Cefotaxim & $15-22$ & 56 & 25 & 48 & 32.43 \\
\hline Ceftazidim & $15-17$ & 56 & 35.8 & 48 & 58.56 \\
\hline Cefoxitin & $15-17$ & 56 & 11.1 & 48 & 37.95 \\
\hline Cefuroxim & $15-17$ & 56 & 35.14 & 48 & 50 \\
\hline Cefuroxim + Sulbactam & $15-17$ & 56 & 0 & 48 & 4.16 \\
\hline Overall resistance rate (\%) & & 27.72 & & 35.49 & \\
\hline
\end{tabular}

Table 4: Distribution of ESBL, AmpC and carbapenemase producing Enterobacteria infection among isolates 


\begin{tabular}{|c|c|c|c|c|c|c|c|c|c|}
\hline \multirow{2}{*}{$\begin{array}{l}\beta \\
\text { lactamase }\end{array}$} & \multicolumn{8}{|c|}{ Enterobacteriaceae species, N (\%) } & \multirow{2}{*}{$\begin{array}{l}\text { Total } \\
(\%)\end{array}$} \\
\hline & E. coli & $\begin{array}{l}\text { Klebsiella } \\
\text { spp }\end{array}$ & $\begin{array}{l}\text { Salmonella } \\
\text { spp }\end{array}$ & $\begin{array}{l}\text { P. } \\
\text { rettgeri }\end{array}$ & $\begin{array}{l}\text { Serratia } \\
\text { spp }\end{array}$ & $\begin{array}{l}\text { Enterobacter } \\
\text { spp }\end{array}$ & $\begin{array}{l}\text { C. } \\
\text { freundii }\end{array}$ & $\begin{array}{l}\text { Proteus } \\
\text { spp }\end{array}$ & \\
\hline Wild & 7 & 3 & 1 & 1 & 1 & 3 & 2 & 2 & $\begin{array}{l}20 \\
(19.23)\end{array}$ \\
\hline Pen TEM & 3 & 4 & 0 & 0 & 3 & 2 & 0 & 2 & $\begin{array}{l}14 \\
(13.33)\end{array}$ \\
\hline Pen RI & 6 & 3 & 0 & 0 & 4 & 1 & 1 & 2 & $\begin{array}{l}17 \\
(16.19)\end{array}$ \\
\hline ESBL & $\begin{array}{l}9 \\
(34.61)\end{array}$ & $\begin{array}{l}3 \\
(11.54)\end{array}$ & $\begin{array}{l}2 \\
(7.69)\end{array}$ & $\begin{array}{l}0 \\
(0.00)\end{array}$ & $\begin{array}{l}2 \\
(7.69)\end{array}$ & $\begin{array}{l}4 \\
(15.38)\end{array}$ & $\begin{array}{l}3 \\
(11.54)\end{array}$ & $\begin{array}{l}3 \\
(11.54)\end{array}$ & $\begin{array}{l}26 \\
(24.76)\end{array}$ \\
\hline AmpC & $\begin{array}{l}9 \\
(40.91)\end{array}$ & $4(18.18)$ & $\begin{array}{l}0 \\
(0.00)\end{array}$ & $\begin{array}{l}0 \\
(0.00)\end{array}$ & $\begin{array}{l}2 \\
(9.09)\end{array}$ & $\begin{array}{l}4 \\
(18.18)\end{array}$ & $\begin{array}{l}2 \\
(9.09)\end{array}$ & $\begin{array}{l}1 \\
(4.54)\end{array}$ & $\begin{array}{l}22 \\
(20.95)\end{array}$ \\
\hline Carbap A & 2 & 0 & 0 & 0 & 0 & 0 & 0 & 0 & $\begin{array}{l}2 \\
(1.90)\end{array}$ \\
\hline MBL & 2 & 1 & 0 & 0 & 0 & 0 & 0 & 0 & $\begin{array}{l}3 \\
(2.86)\end{array}$ \\
\hline $\begin{array}{l}\text { Total } \\
\text { Carbap }\end{array}$ & $\begin{array}{l}4 \\
(80)\end{array}$ & $\begin{array}{l}1 \\
(20)\end{array}$ & $\begin{array}{l}0 \\
(0.00)\end{array}$ & $\begin{array}{l}0 \\
(0.00)\end{array}$ & $\begin{array}{l}0 \\
(0.00)\end{array}$ & $\begin{array}{l}0 \\
(0.00)\end{array}$ & $\begin{array}{l}0 \\
(0.00)\end{array}$ & $\begin{array}{l}0 \\
(0.00)\end{array}$ & $\begin{array}{l}5 \\
(4.76)\end{array}$ \\
\hline Total & 38 & 18 & 3 & 1 & 12 & 14 & 8 & 10 & 104 \\
\hline
\end{tabular}

Pen TEM : Penicillinase TEM, Pen RI : Penicillinase resistant to inhibitors, ESBL : Extended spectrum beta Lactamases, AmpC: AmpC beta Lactamases, Carbap A : Carbapenemase class A, MBL: Metallo beta Lactamases. $C$. fruendii: Citrobacter freundii

\section{Figures}




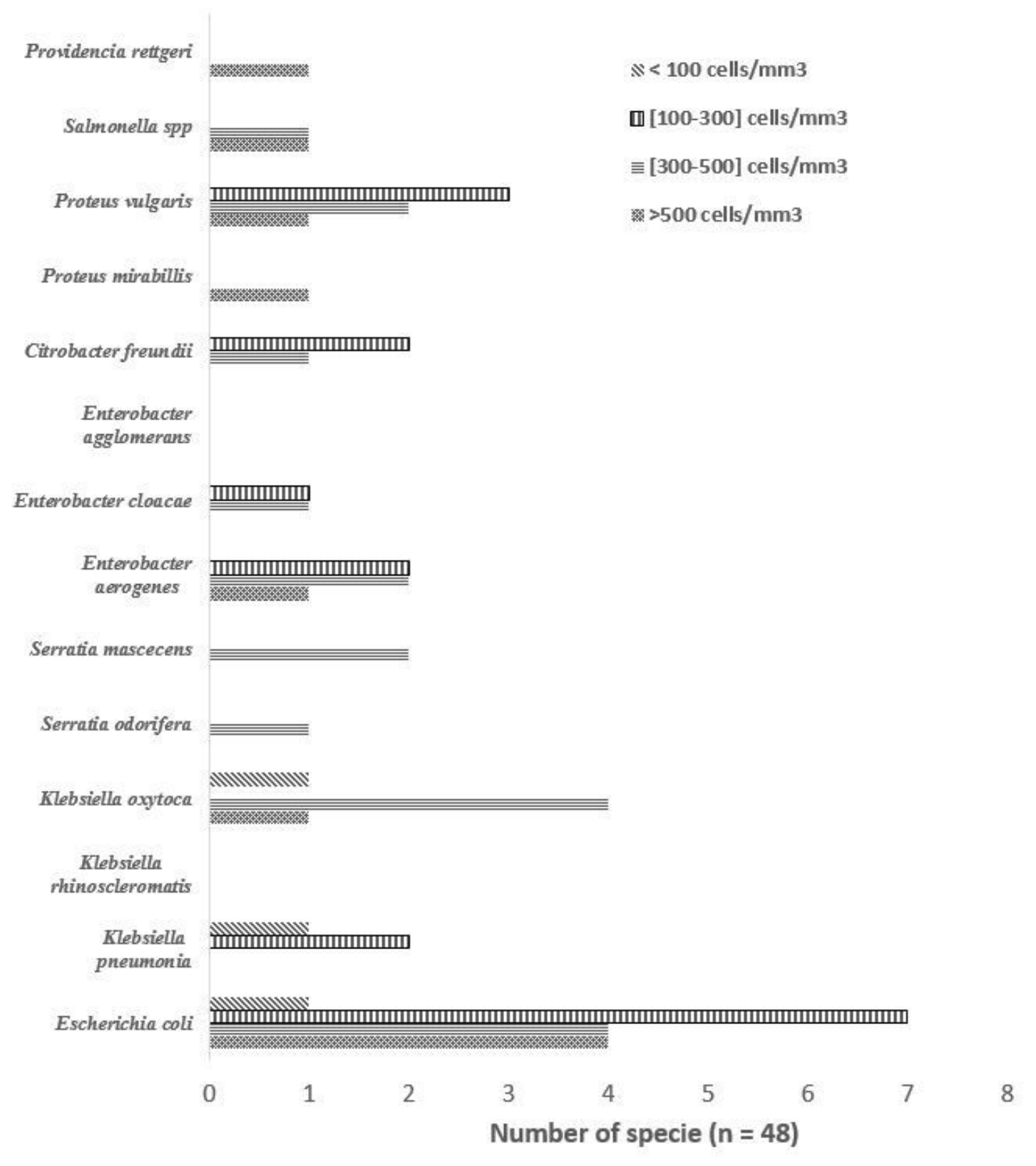

\section{Figure 1}

Enterobacteriaceae isolates among HIV positive patients according to CD4 cell count 
$P=0.0055$

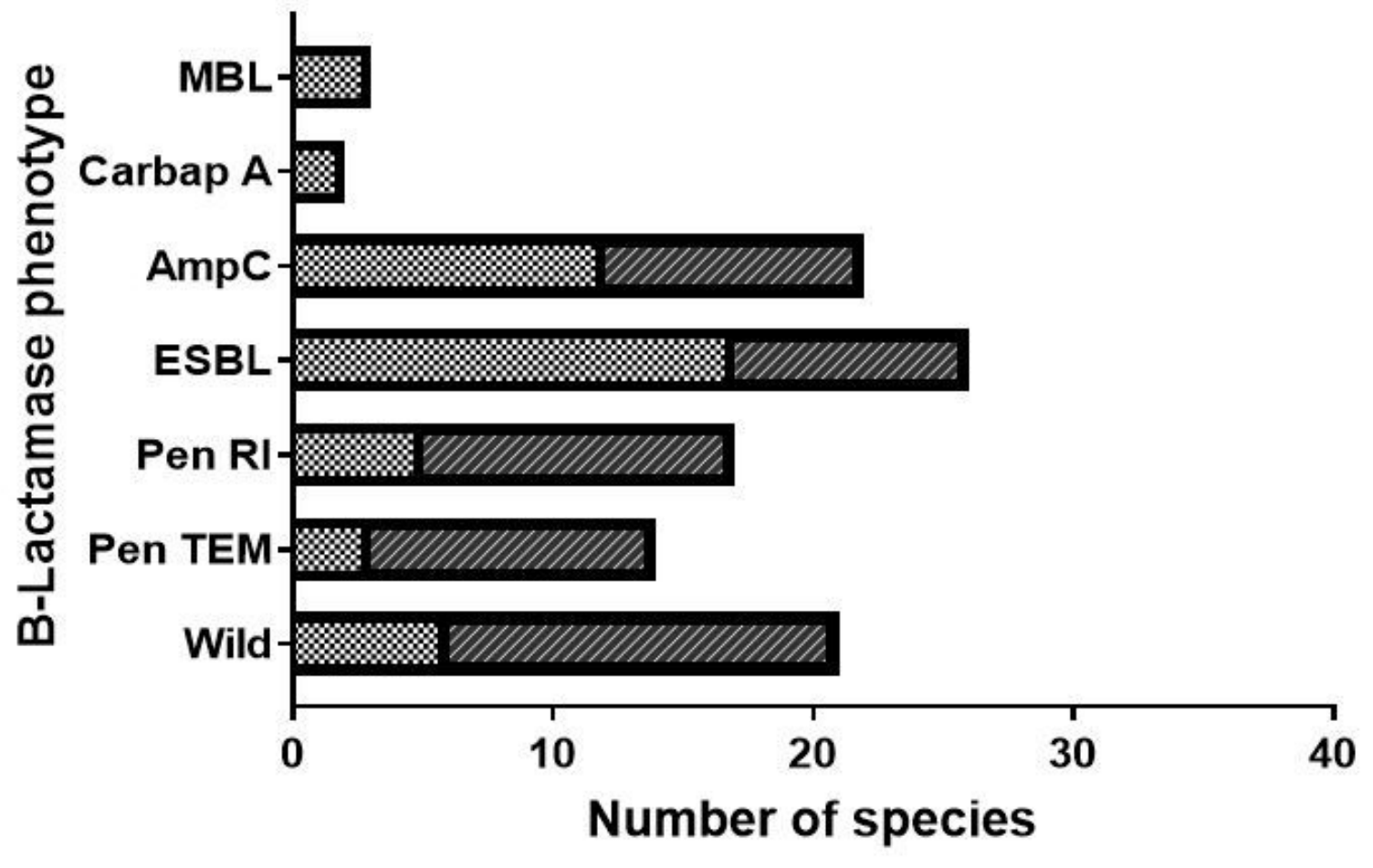

m Hiv-

m Hiv +

\section{Figure 2}

Distribution of $\beta$ lactamase enzyme producing isolates according to HIV status Pen TEM : Penicillinase TEM, Pen RI :

Penicillinase resistant to inhibitors, ESBL : Extended spectrum beta Lactamases, AmpC: AmpC beta Lactamases, Carbap A : Carbapenemase class A, MBL: Metallo beta Lactamases. 